\title{
Multidisciplinary Design Optimization and Analysis of Hydrazine Monopropellant Propulsion System
}

\author{
Amirhossein Adami, ${ }^{1}$ Mahdi Mortazavi, ${ }^{1}$ Mehran Nosratollahi, ${ }^{2}$ \\ Mohammadreza Taheri, ${ }^{3}$ and Jalal Sajadii ${ }^{4}$ \\ ${ }^{1}$ Amirkabir University of Technology, Tehran 15875-4413, Iran \\ ${ }^{2}$ Space Research Institute, Tehran, Iran \\ ${ }^{3}$ Malek Ashtar University of Technology, Tehran, Iran \\ ${ }^{4}$ Department of Aerospace Engineering, Shahid Beheshti University, Tehran, Iran
}

Correspondence should be addressed to Amirhossein Adami; aha.aerospace@aut.ac.ir

Received 30 January 2015; Revised 16 June 2015; Accepted 17 June 2015

Academic Editor: Martin Tajmar

Copyright (C) 2015 Amirhossein Adami et al. This is an open access article distributed under the Creative Commons Attribution License, which permits unrestricted use, distribution, and reproduction in any medium, provided the original work is properly cited.

\begin{abstract}
Monopropellant propulsion systems are widely used especially for low cost attitude control or orbit correction (orbit maintenance). To optimize the total propulsion system, subsystems should be optimized. Chemical decomposition, aerothermodynamics, and structure disciplines demand different optimum condition such as tank pressure, catalyst bed length and diameter, catalyst bed pressure, and nozzle geometry. Subsystem conflicts can be solved by multidisciplinary design optimization (MDO) technique with simultaneous optimization of all subsystems with respect to any criteria and limitations. In this paper, monopropellant propulsion system design algorithm is presented and the results of the proposed algorithm are validated. Then, multidisciplinary design optimization of hydrazine propulsion system is proposed. The goal of optimization can be selected as minimizing the total mass (including propellant), minimizing the propellant mass (maximizing the Isp), or minimizing the dry mass. Minimum total mass, minimum propellant mass, and minimum dry mass are derived using MDO technique. It is shown that minimum total mass, minimum dry mass, and minimum propellant mass take place in different conditions. The optimum parameters include bedloading, inlet pressure, mass flow, nozzle geometry, catalyst bed length and diameter, propellant tank mass, specific impulse (Isp), and feeding mass which are derived using genetic algorithm (GA).
\end{abstract}

\section{Introduction}

A single propellant is used to produce thrust forces in monopropellant propulsion systems. Hydrazine $\left(\mathrm{N}_{2} \mathrm{H}_{4}\right)$ is known as the most commonly used monopropellant. Isp level is generally considered as the performance of the propulsion system [1-3]. In this regard, hydrazine has a performance of about $20 \%$ higher than hydrogen peroxide as a monopropellant. Hydrazine monopropellant thrusters have been applied to satellites [4-6], upper stages, and launching vehicles and new interest is grown up for small reentry vehicles application $[7,8]$. Hydrazine is readily decomposed into ammonium, hydrogen, and nitrogen through exothermic reactions when it is injected into a specific catalyst. Because hydrazine exothermic reaction starts immediately after contacting with the catalysts, hydrazine monopropellant thrusters have an advantage in quick response, which is adequate for attitude control system $[2,5]$.

Monopropellant propulsion systems usually use blowdown feeding system which demands lower equipment. During thruster activity, the decrease in feeding pressure decreases the thrust level and Isp level. Regulators and separated supply gas tanks are used to keep the performance close to constant during the activity. That means new subsystem is added to the propulsion system. Different objective can be considered to derive the best solution. Higher Isp and lower structure mass are the common examples.

In this paper, the hydrazine monopropellant propulsion system breaks down into three more important subsystems including thruster subsystem, propellant tank subsystem, 
and pressurized feeding subsystem. The design algorithm is introduced based on MDO and the proposed algorithm is validated. Then, optimization algorithm (GA) is used to derive the optimum solution for every required total impulse and thrust level.

\section{Multidisciplinary Design Optimization}

Higher Isp needs higher nozzle length and higher operating pressure that leads to increase in the structural mass of the thruster and the supply tanks. Although propellant mass should be increased to compensate the increase in dry mass, the increase in Isp demands lower propellant masses. In view of system level, optimum condition is related to minimum total mass of propulsion system (dry mass + propellant mass). It means that optimum Isp is not the maximum value and optimum dry mass is not the minimum value.

These conflicts should be managed to derive the optimum solution. Multidisciplinary design optimizations (MDO) techniques such as all at once (AAO), collaborative optimization (CO), bilevel integrated system synthesis (BLISS), and concurrent subspace optimization (CSSO) can solve these conflicts and find the optimum solution. In this paper, every discipline is developed based on AAO framework. AAO is the most basic MDO technique and has wide industrial acceptance [9]. In AAO, control is given to a system-level optimizer that ensures a global objective is met by having a single designer control the entire system. AAO solves the global MDO problem by moving all local-level design variables and constraints away from each discipline to a new system-level optimizer entrusted with optimizing a global objective.

The hydrazine monopropellant propulsion system includes propellant, propellant tank, pressurized gas tank (constant feeding pressure), thruster (including catalyst bed, nozzle, and injector), electronics valves, and the other equipment. Three more important subsystems are introduced as thruster, propellant tank, and pressurized feeding subsystem. Modeling of each subsystem and input-output flow data of every discipline will be introduced.

\section{Hydrazine Decomposition}

Liquid hydrazine has an average density near $1000 \mathrm{~kg} / \mathrm{m}^{3}$. Hydrazine decomposition consists of two important parts. Once in contact with the catalyst, the $\mathrm{N}_{2} \mathrm{H}_{4}$ propellant decomposes according to

$$
\begin{aligned}
3 \mathrm{~N}_{2} \mathrm{H}_{4} \stackrel{\text { Catalyst }}{\longrightarrow} & 4 \mathrm{NH}_{3}(\mathrm{~g})+\mathrm{N}_{2}(\mathrm{~g}) \\
& + \text { Heat }(36.3 \mathrm{kcal})
\end{aligned}
$$
via

Then, a part of the ammonia, $\mathrm{NH}_{3}$, is further decomposed

$$
4 \mathrm{NH}_{3} \longrightarrow 2 \mathrm{~N}_{2}+6 \mathrm{H}_{2}-\text { Heat }(19.9 \mathrm{kcal})
$$

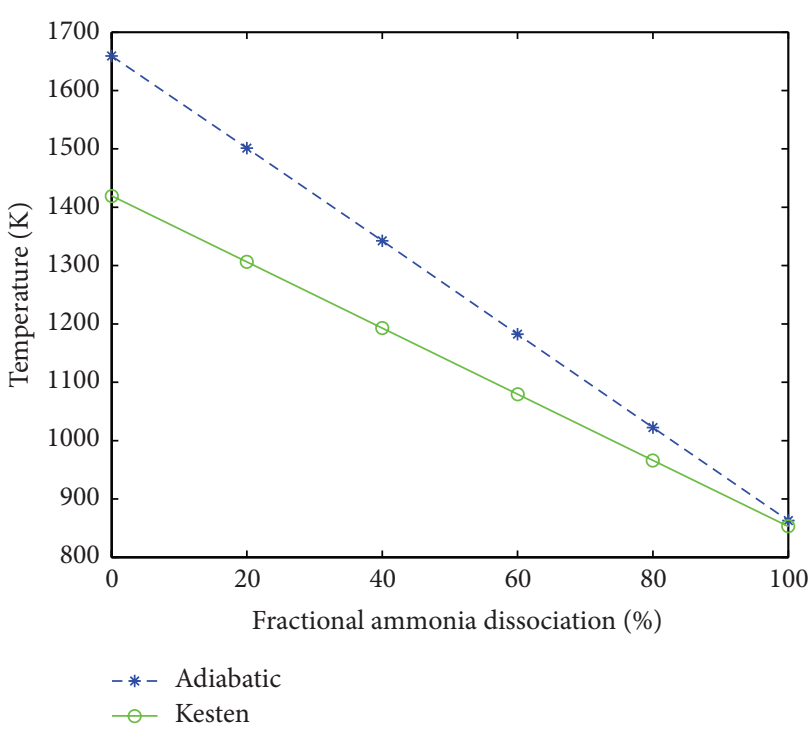

FIGURE 1: Variation of total temperature with $\mathrm{NH}_{3}$ decomposition percent.

Equation (1) shows that heat is released from decomposition process but (2) shows that heat is dropped by decomposition of ammonia. The amount of ammonia decomposition should be controlled by the design of the catalyst bed geometry. Lower ammonia dissociation is achieved by maximum specific impulse, while high ammonia dissociation decreases molecular weight of the gaseous products, which is useful in gas generation applications. Accordingly, hydrazine decomposition is presented in

$$
\begin{aligned}
& \mathrm{N}_{2} \mathrm{H}_{4} \longrightarrow \frac{4}{3} \mathrm{NH}_{3}+\frac{1}{3} \mathrm{~N}_{2}(1) \\
& \left.\begin{array}{l}
\frac{4}{3} \mathrm{NH}_{3} \longrightarrow 2 \mathrm{H}_{2}+\frac{2}{3} \mathrm{~N}_{2}(2)
\end{array}\right\} \stackrel{\text { from (1)+\%x(2) }}{\longrightarrow} \mathrm{N}_{2} \mathrm{H}_{4} \\
& \longrightarrow \frac{4}{3}(1-x) \mathrm{NH}_{3}+\frac{1}{3}(1+2 x) \mathrm{N}_{2}+2 x \mathrm{H}_{2}
\end{aligned}
$$

where $x$ is the percent of $\mathrm{NH}_{3}$ decomposition. Total temperature depends on the percent of $\mathrm{NH}_{3}$ decomposition. Two methods, namely, Adiabatic and Kesten [12], are used to derive the total temperature. Figure 1 illustrates the variation of the total temperature with $\mathrm{NH}_{3}$ decomposition present.

Molecular mass and $\gamma$ are almost similar in the two methods as shown in Figure 2.

The results of Kesten's method are more acceptable and have reasonable accuracy in experiments as shown in Figure 3.

Table 1 presents the relation between temperature, molecular mass, and decomposition percent of $\mathrm{NH}_{3}$ [7].

\section{Propellant Tank Modeling}

Spherical tanks have lower mass in comparison with cylindrical types. Cylindrical tanks demand lower diameters and simpler production procedures. Propellant tank configuration is limited with maximum permitted diameter. If spherical tank 


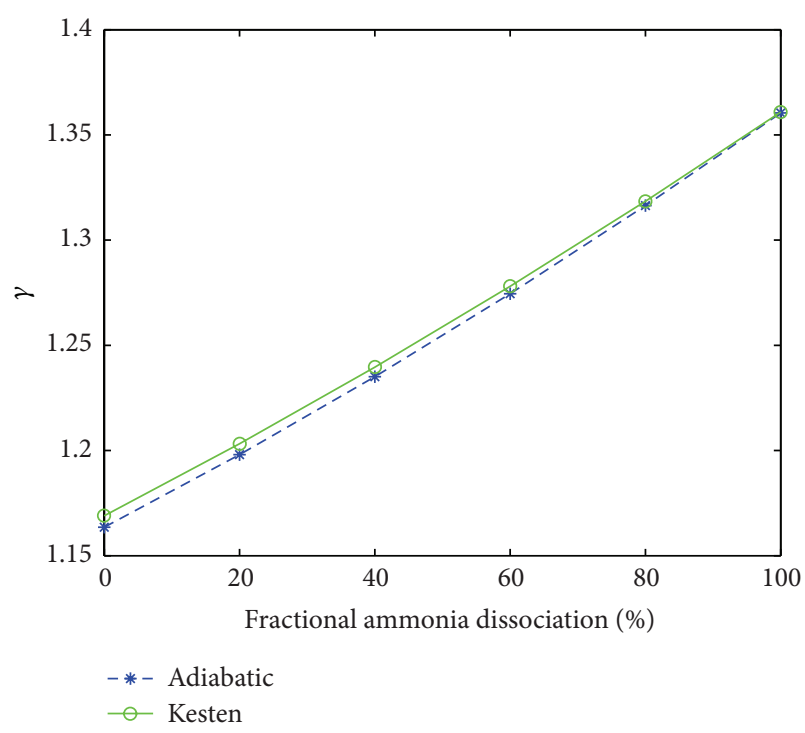

FIGURE 2: Variation of $\gamma$ with $\mathrm{NH}_{3}$ decomposition percent.

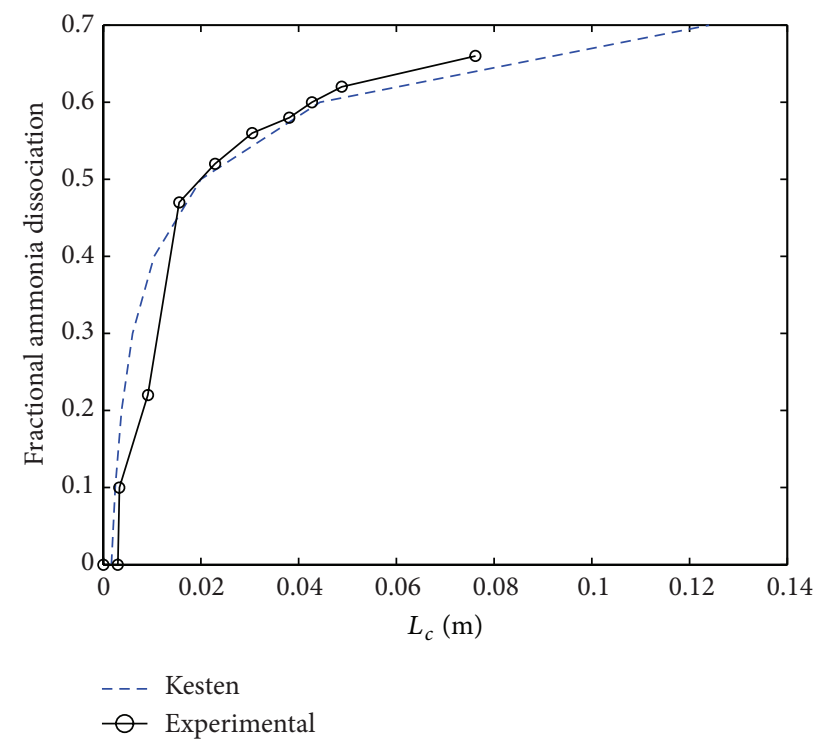

FIGURE 3: Variation of $\mathrm{NH}_{3}$ decomposition percent with catalyst bed length.

TABLE 1: $\mathrm{NH}_{3}$ decomposition and Adiabatic temperature.

\begin{tabular}{lcccccc}
\hline $\begin{array}{l}\mathrm{NH}_{3} \text { decomposition } \\
\text { percent }\end{array}$ & $0 \%$ & $20 \%$ & $40 \%$ & $60 \%$ & $80 \%$ & $100 \%$ \\
\hline Adiabatic temp. $(\mathrm{K})$ & 1659 & 1501 & 1342 & 1183 & 1023 & 863.1 \\
\hline Kesten temp. $(\mathrm{K})$ & 1420 & 1306 & 1193 & 1080 & 966.2 & 852.8 \\
\hline Molecular mass & 19.2 & 16.55 & 14.54 & 12.97 & 11.71 & 10.67 \\
\hline$\gamma$ & 1.169 & 1.203 & 1.24 & 1.278 & 1.318 & 1.361 \\
\hline
\end{tabular}

cannot provide the required volumes then cylindrical tank with maximum permitted diameter and suitable length is

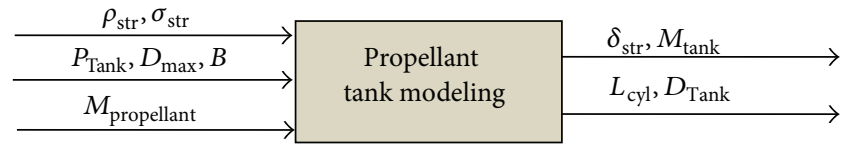

FIGURE 4: Input-output flow data of propellant tank subsystem modeling.

considered. Equation (4) presents the calculation of the tank volume and configuration selection method as follows:

$$
\begin{aligned}
\text { if } V_{\text {Tank }} & \leq \frac{4 \pi R_{\max }^{3}}{3} \Longrightarrow R_{\text {Tank }}=\sqrt[3]{\frac{3 V_{\text {Tank }}}{4 \pi}} \\
\text { if } V_{\text {Tank }}>\frac{4 \pi R_{\max }^{3}}{3} & \\
& \Longrightarrow\left\{\begin{array}{l}
R_{\text {Tank }}=R_{\max } \\
L_{\text {cyl }}=\frac{\left(V_{\text {Tank }}-4 \pi R_{\max }^{3} / 3\right)}{\pi R_{\max }^{2}} .
\end{array}\right.
\end{aligned}
$$

Propellant tank mass is related to tank configuration, tank pressure, filling factor, and propellant volume. Equations and modeling of the propellant tank are introduced by [7]. Aluminum or titanium structures are commonly used for space application but lower cost of aluminum provides more interest. Propellant tank mass is estimated by

$$
\begin{aligned}
M_{\text {Tank }} & =\left(4 \pi R_{\text {Tank }}^{2}+2 \pi R_{\text {Tank }} L_{\text {cyl }}\right) \rho_{\text {str }} \delta_{\text {Tank }}, \\
\delta_{\text {sph }} & =\frac{n_{\text {S.F }}}{2 \sigma_{\text {str }}} P_{\text {Tank }} R_{\text {Tank }}, \\
\delta_{\text {cyl }} & =2 \delta_{\text {sph }} .
\end{aligned}
$$

Input-output flow data of propellant tank model is finally presented in Figure 4.

\section{Pressurized Feeding Modeling}

The feeding subsystem should produce the safe continuance or discontinuance propellant flow to the catalyst bed (thruster). A separate gas tank, usually helium, pressurizes the hydrazine to flow to the catalyst bed. Constant thrust level is usually considered in conceptual design phase. It needs constant feeding pressure and, therefore, regulator is used to keep the propellant tank pressure close to the desired values. The feeding subsystems consist of feed lines (tubes and ducting), regulator, valves, tank, and pressurizer gas. Some of these components can be ignored in the conceptual phase because of having the same effect in various concepts [1]. Most parts of the feeding subsystem mass (changing by concepts) are connected to the gas tank mass and pressurizer gas mass $[1,2]$. The volume of propellant tank and feeding pressure specify the feeding subsystem geometry and mass. 


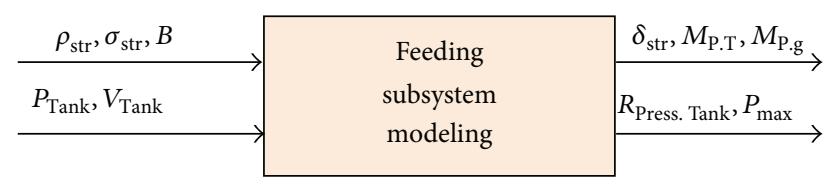

FIGURE 5: Input-output flow data of feeding subsystem modeling.

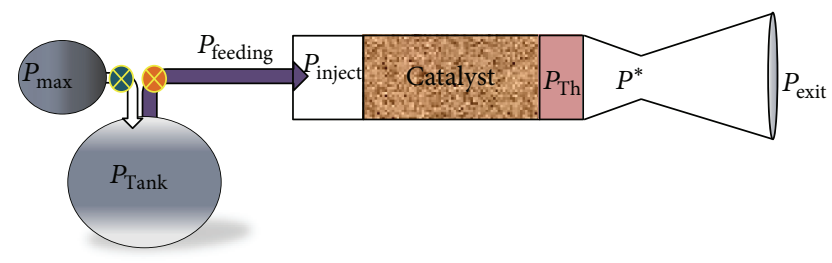

FIGURE 6: Introducing pressure of different propulsion system parts.

The required radius of the gas tank is derived using (6). Complete modeling of pressure feeding subsystem was introduced by [7]

$$
\begin{aligned}
V_{\text {Press.Tank }}^{(t=0)} & =\frac{M_{\text {P.G }}(\text { total })-M_{\text {Press.Gas }}^{(t=0)}}{P_{\max } / \text { RT }} \\
& =\frac{\operatorname{RT}\left(M_{\text {P.G }}(\text { total })-M_{\text {Press.Gas }}^{(t=0)}\right.}{P_{\max }} \\
R_{\text {Press.Tank }} & =\sqrt[3]{\frac{3 V_{\text {Press.Tank }}^{(t=0)}}{4 \pi}} .
\end{aligned}
$$

Titanium structure is selected for pressurized tank because of high pressure, which demands thicker structure. Mass penalty of using aluminum is considerable. Feeding subsystem mass is estimated from

$$
\begin{aligned}
M_{\text {feeding }} & =M_{\text {P.T }}+M_{\text {P.G }}, \\
M_{\text {P.T }} & =4 \pi R_{\text {P.T }}^{2} \rho_{\text {str }} \delta_{\text {P.T }}, \\
\delta_{\text {P.T }} & =\frac{n_{\text {S.F }}}{2 \sigma_{\text {str }}} P_{\max } R_{\text {P.T }}, \quad P_{\max } \leq 200 \text { (bar), } \\
M_{\text {P.G }} & =\frac{4 P_{\max }}{3 R_{\text {gas }} T_{\text {P.G }}} \pi R_{\text {P.T }}^{3} \rho_{\text {str }} .
\end{aligned}
$$

Input-output flow data of feeding subsystem modeling is finally presented in Figure 5.

\section{Thruster Subsystem Modeling}

Thrusters consist of catalyst, catalyst bed, and nozzle. Thruster designing is one of the most important parts of every propulsion system. Thrust level and Isp introduce the thruster size and performance, respectively. Pressures of different parts of propulsion system are introduced in Figure 6 which will be used to derive the mathematical model.

$P_{\mathrm{Th}}$ is the pressure after catalyst bed and before nozzle. Thrust level and Isp introduce the thruster size and
TABLE 2: Some properties of the selected catalyst [2].

\begin{tabular}{lc}
\hline$L_{f}^{\max }\left(\mathrm{kg} / \mathrm{m}^{2} \cdot \mathrm{s}\right)$ & $\sim 450$ \\
\hline Density $\left(\mathrm{kg} / \mathrm{m}^{3}\right)$ & $\sim 2450$ \\
\hline
\end{tabular}

performance, respectively. The mentioned parameters are calculated by

$$
\begin{aligned}
& T_{\mathrm{vac}}=\frac{A^{*} P_{e}\left(\gamma M_{e}^{2}+1\right)}{M_{e}}\left[\frac{2}{\gamma+1}(1\right. \\
& \left.\left.+\frac{\gamma-1}{2} M_{e}^{2}\right)\right]^{(\gamma+1) / 2(\gamma-1)}, \\
& \text { Isp }_{\mathrm{vac}}=\frac{T_{\mathrm{vac}}}{\dot{m} g_{0}} .
\end{aligned}
$$

Steel structure is commonly used for thruster. Heat control of hydrazine monopropellant thruster is usually ignored because of the short time activity and low temperature in comparison with bipropellant and solid propellant thrusters.

6.1. Catalyst. Catalyst is the most important part of every monopropellant thruster. Actually, development of monopropellant thrusters depends on development of suitable catalysis. Shell Company (1963) introduced the first spontaneous hydrazine decomposition catalyst. It was a rutheniumiridium catalyst with $2.1-28 \%$ active metal on activated charcoal; one example consisted of $3.7 \% \mathrm{Ru}$ and $4.3 \% \mathrm{Ir}$ on activated charcoal. The most active catalysts described are those containing iridium or a mixture of iridium and ruthenium as active metals. The majority of work on hydrazine decomposition catalyst has been conducted with Shell 405 (32\% iridium over support of alumina $\mathrm{Al}_{2} \mathrm{O}_{3}$ ) which is capable of surviving several hundred cold starts with no significant degradation. It is considered the most successful hydrazine decomposition catalyst to date thus; similar catalyst is considered in this study. Cost decreasing of hydrazine catalyst is one of the most important objectives in catalysts research nowadays $[13,14]$. For more information readers are referred to $[2,15]$. The most important characteristic of catalyst is the ability to decompose propellant flow (named catalyst bed-loading factor) with lower required residence time. Table 2 shows some physical parameters of the considered catalyst.

6.2. Catalyst Bed. Cylindrical bed is considered in this paper. Length and diameter of the catalyst bed introduce the geometry. The required thickness is specified by maximum pressure in catalyst bed. The important event in catalyst bed is pressure drop during the injection and movement through the catalyst bed. Three more important pressure losses between propellant tank and thruster are pipe and feeding pressure drop, injector pressure drop, and catalyst 
pressure drop. Equation (9) shows the relation between propellant tank pressure and thruster pressure $[7,16,17]$ :

$$
\begin{aligned}
& P_{\text {Tank }}=P_{\text {Th }}+\Delta P_{\text {ctl }}+\Delta P_{\text {inj }}+\Delta P_{\text {pipe }}, \\
& \Delta P_{\text {ctl }}=\frac{2 L_{f}}{\rho r_{p}}\left(\frac{1-\varphi}{\varphi^{3}}\right)\left[\frac{300(1-\varphi) \mu}{r_{p}}+1.75 L_{f}\right] L_{\text {ctl }}, \\
& L_{\text {ctl }}=\frac{64.7993 L_{f}}{(1-\varphi)}\left[\left(0.663\left(2 r_{p}\right)^{0.17}-0.17\right)\right. \\
& \left.\cdot\left(\frac{6.803}{P_{\text {inj }}(\text { bar })}\right)^{0.22}+0.17\right]^{-3.5714}, \\
& L_{\text {Th }}=1.2 L_{\text {ctl }}, \\
& \Delta P_{\text {pipe }}=0.5 \text { bar, } \\
& P_{\text {inj }}=P_{\text {Tank }}-\Delta P_{\text {pipe }}, \\
& \Delta P_{\text {inj }}=0.2\left(P_{\text {Tank }}-\Delta P_{\text {pipe }}\right),
\end{aligned}
$$

where $\varphi$ is the percent decomposition of $\mathrm{NH}_{3}$. Catalyst bed length and diameter depend on thruster pressure and mass flow, but it should be noted that pressure drop in catalyst bed is related to bed-loading factor. This event conflicts with thruster performance.

6.3. Divergent-Convergent Nozzle. High pressure and temperature flow exits the catalyst bed and enters the D-C nozzle which changes the potential energy to the kinetic energy. Conical nozzle is selected for conceptual design phases. Divergence half angle of cone, diameter of the catalyst bed, throat diameter, convergence half angle of cone, and the exit diameter introduce the nozzle geometry. The geometry parameters are shown in Figure 7.

Geometry parameters correlate with thermodynamic parameters. Equation (10) presents the relation between geometry parameters and thermodynamic parameters:

$$
\begin{aligned}
\theta_{1} & =45^{\circ}, \\
\theta_{2} & =15^{\circ}, \\
A^{*} & =\frac{\dot{m} \sqrt{T_{c} R / \gamma}}{P_{\mathrm{Th}}}\left(1+\frac{\gamma-1}{2}\right)^{(\gamma+1) / 2(\gamma-1)}, \\
A_{e} & =\frac{A^{*}}{M_{e}}\left[\frac{2}{\gamma+1}\left(1+\frac{\gamma-1}{2} M_{e}^{2}\right)\right]^{(\gamma+1) / 2(\gamma-1)}, \\
A_{e} & =A^{*} Z_{\text {expansion }}, \\
L_{\text {div }} & =\frac{R_{\mathrm{ctl}}-R_{t}}{\tan \theta_{1}}, \\
L_{\text {div }} & =\frac{R_{e}-R_{t}}{\tan \theta_{2}} .
\end{aligned}
$$

Total thruster mass (catalyst, catalyst bed, and nozzle) is estimated from

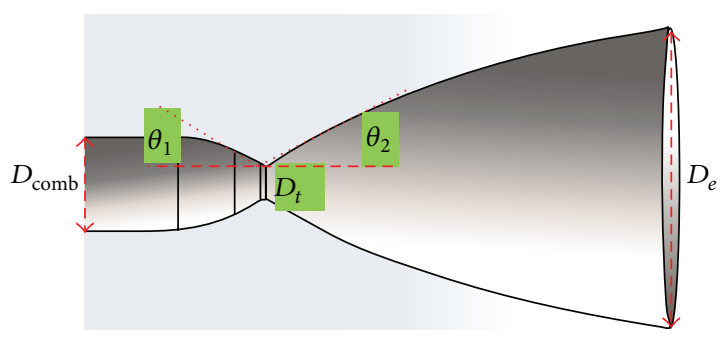

FIGURE 7: Geometry parameters of the nozzle.

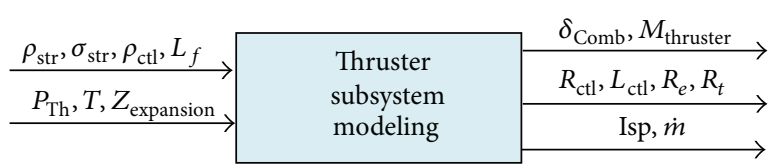

FIGURE 8: Input-output flow data of thruster subsystem modeling.

$$
\begin{aligned}
& M_{\text {Thruster }}=M_{\text {Comb }}+M_{\text {Nozzle }}+M_{\text {cat }}, \\
& M_{\text {Comb }}=\left(2 \pi R_{\mathrm{ctl}} L_{\mathrm{ctl}}+\pi R_{\mathrm{ctl}}^{2}\right) \delta_{\mathrm{Comb}} \rho_{\mathrm{str}}, \\
& M_{\text {Nozzle }} \\
& \quad=\left[\frac{\pi}{\tan \theta_{1}}\left(R_{\mathrm{ctl}}^{2}-R_{t}^{2}\right)+\frac{\pi}{\tan \theta_{2}}\left(R_{e}^{2}-R_{t}^{2}\right)\right] \delta_{\mathrm{Comb}} \rho_{\mathrm{str}}, \\
& \delta_{\mathrm{Comb}}=\frac{n_{\mathrm{S} . \mathrm{F}}}{\sigma_{\mathrm{str}}}\left(\frac{\pi P_{\mathrm{Th}} R_{\mathrm{ctl}}^{2}+T}{\pi R_{\mathrm{ctl}}}\right), \\
& M_{\mathrm{cat}}=\rho_{\mathrm{ctl}} A_{c} L_{\mathrm{ctl}} .
\end{aligned}
$$

Finally input-output flow data of thruster modeling is presented in Figure 8.

\section{Validation of the Proposed Design Algorithm}

Modeling of each part of propulsion system should be complex enough to have an acceptable estimation of the total mass, geometry, and performance. Results of the design algorithm can be converted to real monopropellant thruster's data by using some correction factors. The correction factors (and suitable values) are presented as follows: $[18,19]$

$$
\begin{aligned}
& \text { Thrust }_{\text {real }}=\lambda_{1} \text { Thrust }_{\text {Ideal }}, \\
& T_{0}^{\text {real }}=\lambda_{2}^{2} T_{0}^{\text {Adiabatic }}, \\
& M_{\text {Total }}=n_{\sigma}\left(M_{\text {Thruster }}+M_{\text {feeding }}+M_{\text {Tank }}\right), \\
& \lambda_{1}=0.95 \text { Nozzle Correction Factor, } \\
& \lambda_{2}=0.90 \text { Adiabatic Temp. Correction Factor, } \\
& n_{\sigma}=1.55 \text { Other Equipment. }
\end{aligned}
$$

Comparison between operational thrusters' data and proposed design algorithm is summarized in Table 3. It should be noted that Table 3 shows the redesign results only and 
TABLE 3: Results of comparison of real thrusters and proposed design algorithm [10, 11].

\begin{tabular}{|c|c|c|c|c|}
\hline Parameters & $\begin{array}{l}\text { Redesign of } 2 \mathrm{nd} \\
\text { thruster }(400 \mathrm{~N})\end{array}$ & $\begin{array}{l}\text { 2nd existence thruster } \\
\qquad(400 \mathrm{~N})\end{array}$ & $\begin{array}{l}\text { Redesign of first } \\
\text { thruster }(10 \mathrm{~N})\end{array}$ & $\begin{array}{l}\text { First existence } \\
\text { thruster }(10 \mathrm{~N})\end{array}$ \\
\hline Pic & - & & - & 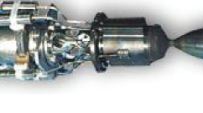 \\
\hline Mass with valve & 2506 (gr) & 2700 (gr) & 190 (gr) & 240 (gr) \\
\hline Catalyst bed pressure & 26 (bars) & 6 26 (bars) & 22 (bars) & 5.5 22 (bars) \\
\hline Mass flow & $196(\mathrm{gr} / \mathrm{s})$ & $182(\mathrm{gr} / \mathrm{s})$ & $4.4(\mathrm{gr} / \mathrm{s})$ & $4.4(\mathrm{gr} / \mathrm{s})$ \\
\hline Catalyst bed length & $5.9(\mathrm{~cm})$ & $\sim$ & $2(\mathrm{~cm})$ & $2.4(\mathrm{~cm})$ \\
\hline Nozzle length & $14.4(\mathrm{~cm})$ & $8.2(\mathrm{~cm})$ & $5.7(\mathrm{~cm})$ & $3.4(\mathrm{~cm})$ \\
\hline Catalyst bed diameter & $6.8(\mathrm{~cm})$ & $6.5(\mathrm{~cm})$ & $1.9(\mathrm{~cm})$ & $1.9(\mathrm{~cm})$ \\
\hline
\end{tabular}

optimization has not been done yet. According to the results of Table 3, presented design algorithm has an acceptable accuracy in modeling mass $(>22 \%)$, geometry $(>19 \%)$, and thermodynamic parameters $(>9 \%)$. The conical nozzle has always longer length in compression with bell types so real models have shorter nozzle length.

As case study, following conditions are considered for multidisciplinary analysis of a monopropellant propulsion system:

$$
\begin{aligned}
I_{\text {Total }} & =4375(\mathrm{~N} \cdot \mathrm{s}), \\
T & =500(\mathrm{~N}), \\
L_{f} & =84, \\
\varphi & =40 \% .
\end{aligned}
$$

Figure 9 illustrates the variation of propellant mass and dry mass with the pressure of catalyst bed for the following conditions.

According to Figure 9, the minimum total mass solution is different from the minimum dry mass solution or the minimum propellant mass solution. The decrease in dry mass occurs by increase in the pressure of thruster because of $L_{f}$ value. The increase in dry mass by increase in the pressure of thruster is seen for low $L_{f}$ values $\left(L_{f}<20\right)$. Finally, lowest total mass is achieved by selecting the pressure of the thruster equal to 10.06 bar.

It should be noted that although mass per cost ratio of structure and propellant may be different, in view of the system level (what is considered in this paper) the propulsion mass parts (dry mass and propellant mass) have a similar effect in the mission cost. Figure 10 illustrates the variation of total mass with Isp for the same conditions.

According to Figure 10, the minimum total mass solution is derived when Isp value equals 215.7 and this value is not the maximum value.

Now, the effects of bed-loading and percent of $\mathrm{NH}_{3}$ decomposition are taken into account. Figure 11 shows the effect of bed-loading on movement of the minimum mass point. According to the results of Figure 11, increase in $L_{f}$ leads to having a heavier total mass and the minimum total mass moves to have lower Isp values. Figure 12 illustrates the

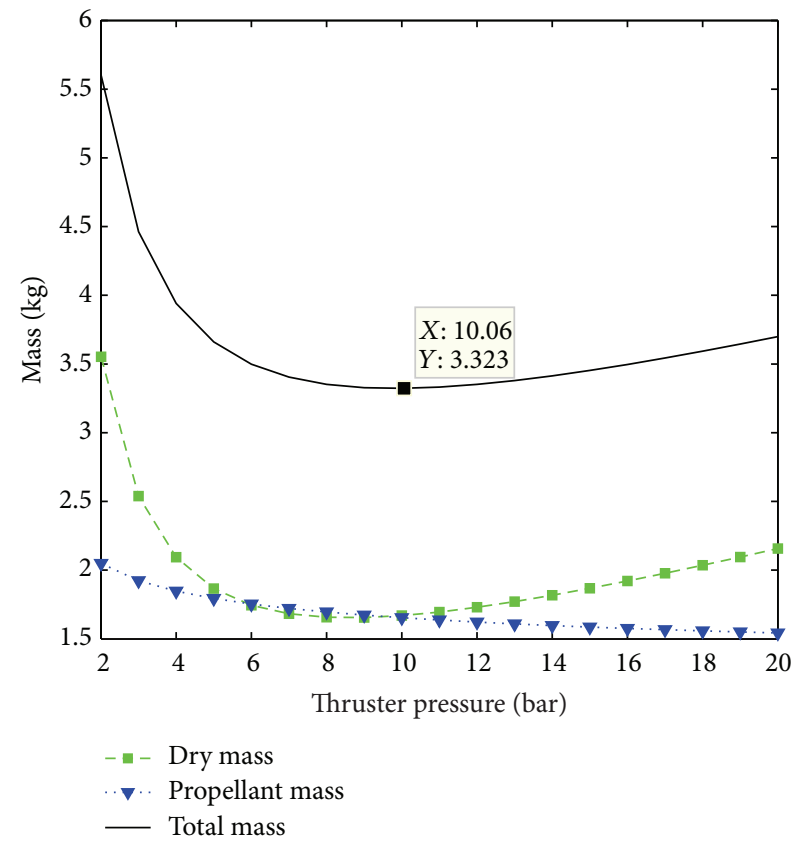

FIGURE 9: Mass variation with the thruster pressure.

effect of percent of $\mathrm{NH}_{3}$ decomposition on movement of the minimum mass point.

According to the results of Figure 12, increase in $\varphi$ leads to having a higher total mass for $\varphi>0.4$. Therefore, it should be tried to keep this parameter as low as possible to have lower total propulsion mass. It should be noted that, by using MDO, the best solution is directly derived and such analysis is not required. The minimum total mass is derived by trading off between minimum propellant mass and minimum dry mass for every required total impulse.

\section{Multidisciplinary Design Optimization of Hydrazine Monopropellant Propulsion System}

Dry mass, Isp, and geometry are recognized as the most important parameters for every propulsion system. The propellant mass plays significant role in the cost of 


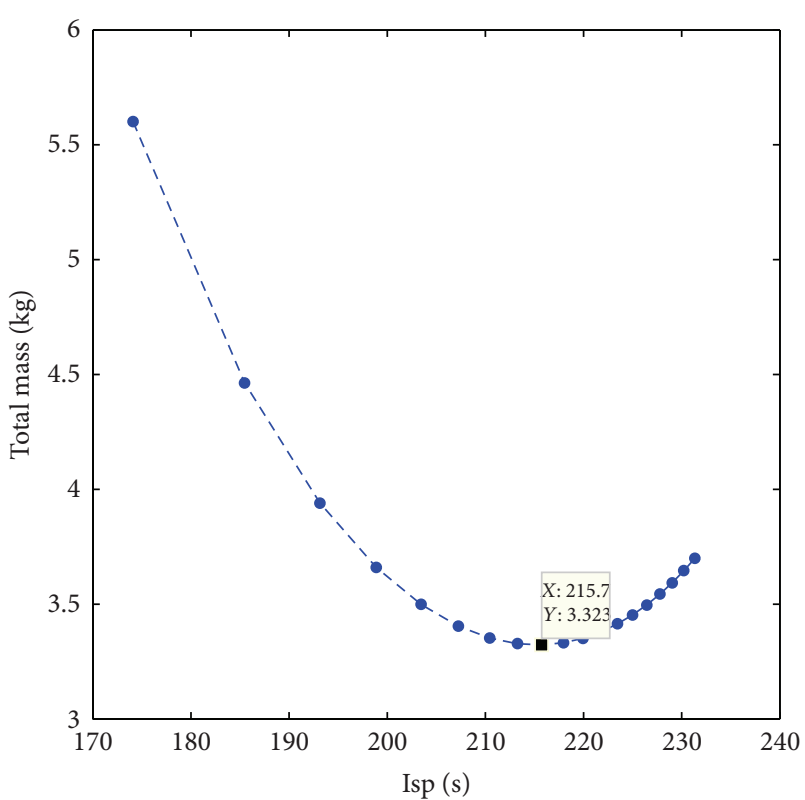

FIgURE 10: Total mass variation with Isp.

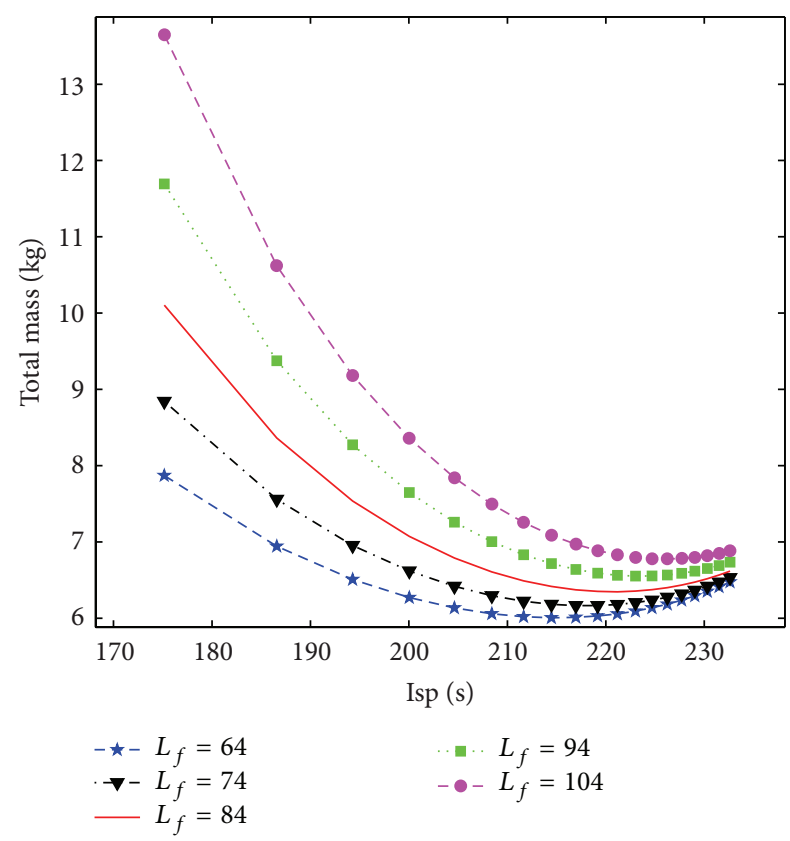

FIgURE 11: Movement of the minimum mass point by variation $L_{f}$.

the mission and propellant tank mass. The optimum design depends on minimum mission cost. It is better to consider the total mass as the cost function in preliminary design phases because the total mass is suitable prediction of the mission cost. The total mass consists of propellant mass and dry mass. Propellant mass is decreased with increase in pressure or decrease in ammonia decomposition percent (Isp), but dry mass has an inverse behavior. Figure 13 illustrates the multidisciplinary design optimization

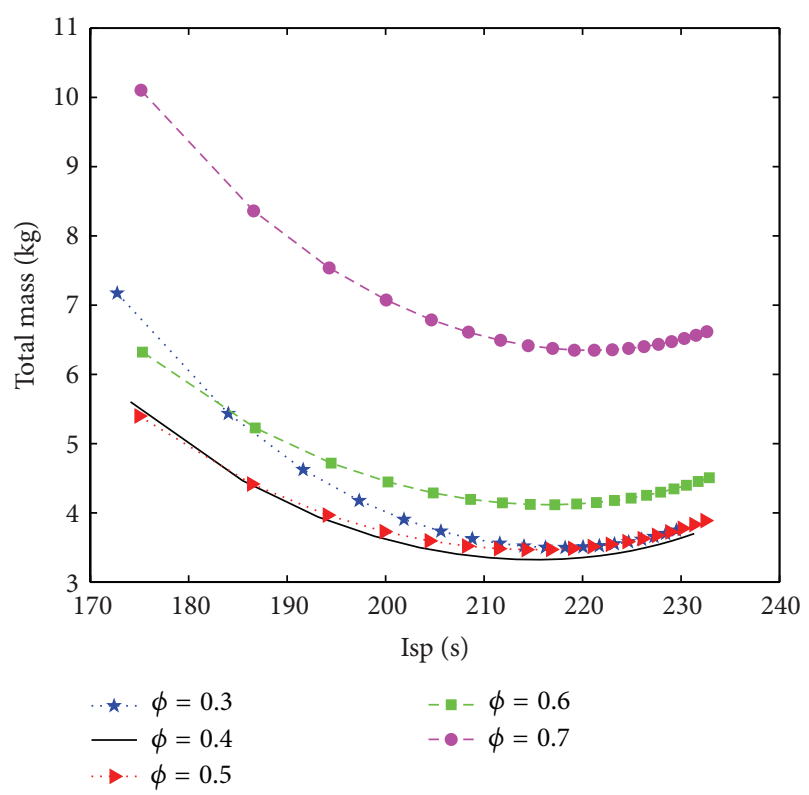

FIGURE 12: Movement of the minimum mass by variation of percent of $\mathrm{NH}_{3}$ decomposition.

algorithm for monopropellant propulsion system based on AAO framework.

As mentioned before, it is considered that $\varphi=55 \%$. Now, similar problem which has been introduced in relation (13) is considered. The optimum solution has been derived by MDO and the results have been summarized in Table 4 .

According to the results of Table 4, the optimum solution has been directly derived with acceptable accuracy in comparison with results of Figures 9 to 11. It is clear that the structure or pressurizer gas can be simply changed to evaluate their effects.

\section{Summary and Conclusions}

In this paper, optimum design algorithm of the hydrazine monopropellant propulsion system is introduced based on all at once (AAO) framework. The results of the proposed algorithm have been justified using some correction factors which are derived by comparison between the results of proposed algorithm and operational thruster's data. Then, the minimum total mass is derived by trading off between the minimum propellant mass and the minimum dry mass for a case study. As the results of this research, it is shown that the minimum total mass solution is derived when Isp is not the maximum value. In addition the effects of two design parameters have been recognized as follows. Increase in $L_{f}$ leads to having a heavier total mass and the minimum total mass point moves to have lower Isp. Increase in $\varphi$ leads to having a higher total mass for $\varphi>0.4$. The proposed algorithm can be used for every required total impulse and thrust level. Finally, MDO technique has been used to directly derive the optimum solution using GA. As the results, MDO has acceptable accuracy and directly finds the optimum solution. 
TABLE 4: Results of multidisciplinary design of hydrazine propulsion system.

\begin{tabular}{lccccc}
\hline $\begin{array}{l}\text { Optimum } \\
\text { pressure }\end{array}$ & Optimum Isp & $\begin{array}{c}\text { Optimum } \\
\text { bed-loading }\end{array}$ & $\begin{array}{c}\text { Minimum total } \\
\text { mass }\end{array}$ & $\begin{array}{c}\text { Optimum } \\
\text { propellant mass }\end{array}$ & Optimum dry mass \\
\hline 10.15 bars & $215.7 \mathrm{sec}$ & 0.38 & $3.34 \mathrm{~kg}$ & $1.64 \mathrm{~kg}$ & $1.67 \mathrm{~kg}$ \\
\hline
\end{tabular}

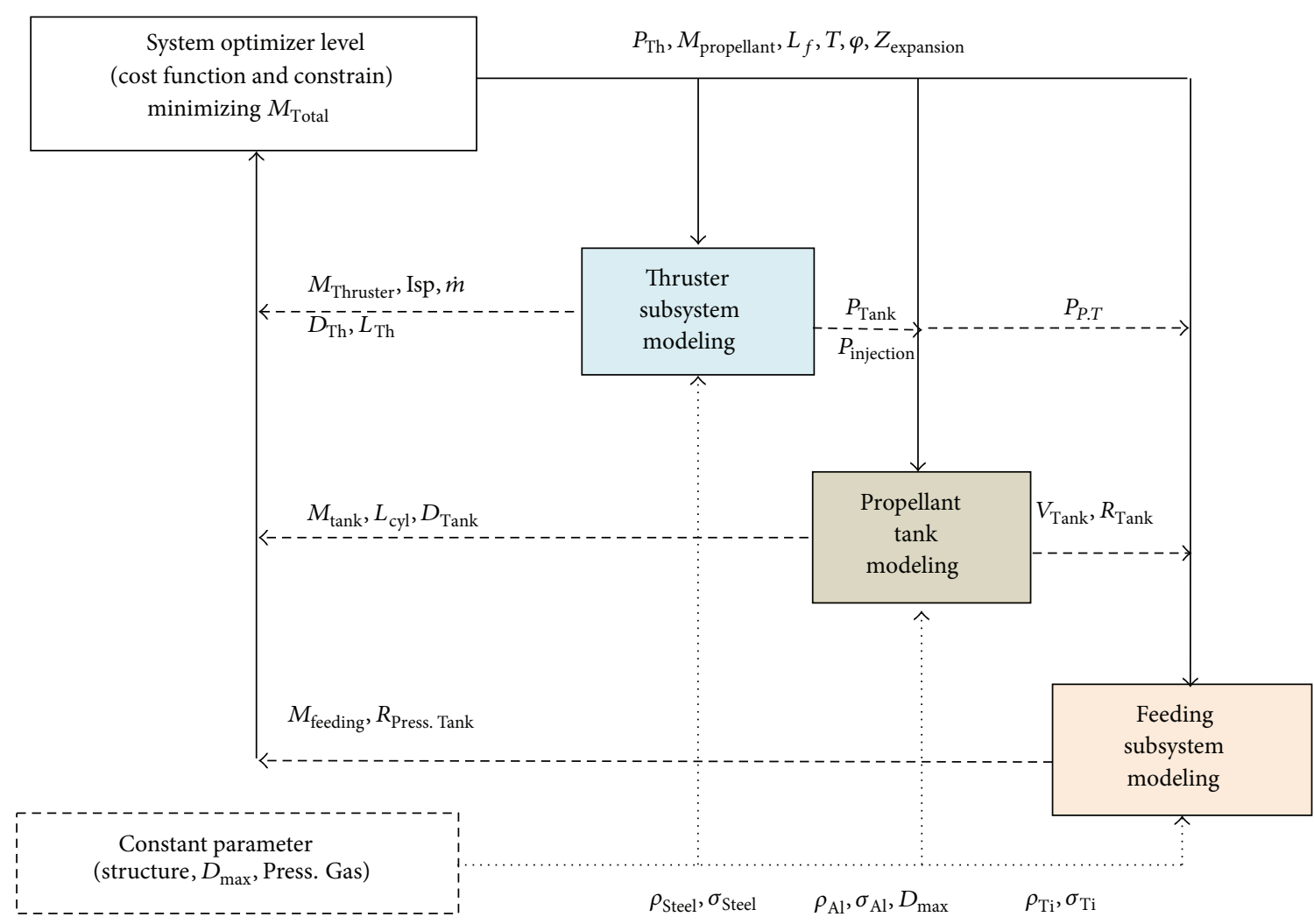

FIGURE 13: Multidisciplinary design optimization algorithm for the hydrazine propulsion system.

\section{Notations}

AAO: All at once

CO: Collaborative optimization

GA: $\quad$ Genetic algorithm

MDO: Multidisciplinary design optimization

BLISS: Bilevel integrated system synthesis

CSSO: Concurrent subspace optimization

$\rho_{\text {str }}: \quad$ Structure density

$A^{*}, R_{t}$ : Throat area, radius of throat

$P_{e}: \quad$ Pressure at exit of the nozzle

$M_{e}: \quad$ Mach number of exit nozzle

$\gamma: \quad$ Isentropic exponent

$\dot{m}$ : Mass Fflow of nozzle

$g_{0}: \quad$ Gravitational acc.

$T_{\text {vac }}$ : Vacuum thrust

$A_{e}, R_{e}$ : Exit area, radius of exit section

$P_{\mathrm{Th}}: \quad$ Pressure of catalyst bed

$n_{\sigma}$ : Other equipment mass fraction

$V_{\text {inj }}$ : Injection velocity of propellant

$M_{\text {Thruster: }}$ : Thruster mass

$\theta_{1}: \quad$ Convergent angle $\theta_{2}: \quad$ Divergent angle

$L_{\mathrm{Th}}: \quad$ Thruster length

$L_{f}$ : $\quad$ Bed-loading

$V_{\text {Tank }}, R_{\text {Tank }}:$ Volume, radius of tank

$L_{\text {cyl }}: \quad$ Cylindrical length of tank

$R_{\max }$ : $\quad$ Maximum permitted radius

$M_{\text {Tank }}$ : $\quad$ Mass of the propellant tank

$x, \varphi: \quad$ Percent of NH3 decomposition

$\delta_{\text {Tank }}: \quad$ Propellant tank thickness

$B: \quad$ Filling factor of tank

$V_{\text {Press.Tank: }}$ Volume of pressurized tank

$R_{\text {Press.Tank }}$ : Radius of pressurized tank

$T_{\infty}$ : Initial temperature

$M_{\text {P.G }}$ : $\quad$ Required mass of pressurizer gas

$P_{\max }: \quad$ Maximum pressure

$\mathrm{M}_{\mathrm{PT}}$ : $\quad$ Mass of the pressurizer tank

$R_{\mathrm{P} . \mathrm{T}}$ : $\quad$ Pressurizer tank's radius

$L_{\mathrm{ctl}}: \quad$ Catalyst bed length

$P_{\text {Tank }}: \quad$ Tanks pressure

$\lambda_{1}$ : $\quad$ Nozzle correction factor

$n_{\text {S.F }}: \quad$ Correction factor

$\lambda_{2}$ : Temperature correction factor 
$M_{\text {cat }}:$ Catalyst mass

$L_{\text {con }}$ : Convergent length of nozzle

$L_{\text {div }}$ : Divergent length of nozzle

$R_{\text {gas }}$ : Constant parameter of pressurizer gas.

\section{Conflict of Interests}

The authors declare that there is no conflict of interests regarding the publication of this paper.

\section{References}

[1] A. Adami, M. Mortazavi, and M. Nosratollahi, "Multidisciplinary design optimization of hydrogen peroxide monopropellant propulsion system using GA and SQP," International Journal of Computer Applications, vol. 113, no. 9, pp. 14-21, 2015.

[2] A. Adami, M. Mortazavi, and M. Nosratollahi, "Multidisciplinary design hybrid optimization of hydrazine monopropellant propulsion system," Aircraft Engineering and Aerospace Technology. In press.

[3] A. Adami, M. Mortazavi, and M. Nosratollahi, "A new approach in multidisciplinary design optimization of upper-stages using combined framework," Acta Astronautica, vol. 114, pp. 174-183, 2015.

[4] A.-S. Yang, "Satellite hydrazine propulsion system design trades," Journal of Da-Yeh University, vol. 10, no. 1, pp. 41-50, 2001.

[5] K.-H. Lee, M.-J. Yu, and J.-M. Choi, "Develoment of monopropellant propulsion system for low earth orbit observation satellite," KSAS International Journal, vol. 6, no. 1, 2005.

[6] D. T. Schmuland, R. K. Masse, and C. G. Sota, "Hydrazine propulsion module for CubeSats," in Proceedings of the 25th Annual AIAA/USU Conference on Small Satellites, SSC11-X-4, August 2011.

[7] A. Adami, Multidicsiplinary design optimization of reentry vehicle considering guidance algorithm [Ph.D. thesis], Amirkabir University of Technology, Tehran, Iran, 2014.

[8] M. Rath, H. D. Schimtz, and M. Steenborg, "Development of a $400 \mathrm{~N}$ hydrazine thruster for ESA's atmospheric reentry demonstrator," in Proceedings of the 32nd AIAA/ASME/SAE/ASEE Joint Propulsion Conference, AIAA-96-2866, Lake Buena Vista, Fla, USA, July 1996.

[9] M. Nosratollahi, M. Mortazavi, A. Adami, and M. Hosseini, "Multidisciplinary design optimization of a reentry vehicle using genetic algorithm," Aircraft Engineering and Aerospace Technology, vol. 82, no. 3, pp. 194-203, 2010.

[10] Astrium Propulsion \& Equipment, $10 \mathrm{~N}$ Mono-Propellant Thruster, Astrium Propulsion \& Equipment, Munich, Germany, 2012.

[11] Astrium Propulsion \& Equipment, 400N Mono-Propellant Thruster, Astrium Propulsion \& Equipment, Munich, Germany, 2012.

[12] A. S. Kesten, "Analytical study of catalytic reactors for hydrazine decomposition," Quarterly Progress Report No 2 Report E910461-6, United Aircraft Research Laboratories, 1966.

[13] J. N. Hinckel, "Low cost catalysts for hydrazine monopropellant thrusters," in Proceedings of the 45th AIAA/ASME/SAE/ASEE Joint Propulsion Conference \& Exhibit, AIAA 2009-5232, Denver, Colo, USA, August 2009.
[14] I.-T. Kim, J.-H. Jung, J.-H. Kim, H.-H. Lee, and J.-W. Lee, "Performance test of hydrazine decomposition catalyst formonopropellant thruster," in Proceedings of the 45th AIAA/ASME/SAE/ASEE Joint Propulsion Conference \& Exhibit, AIAA 2009-5484, Denver, Colo, USA, August 2009.

[15] M. W. Schmidt and M. S. Gordon, "The decomposition of hydrazine in the gas phase and over an iridium catalyst," Zeitschrift fur Physikalische Chemie, vol. 227, no. 11, pp. 13011336, 2013.

[16] A. E. Makled and H. Belal, "Modeling of hydrazine decomposition for monopropellant thrusters," in Proceedings of the 13th International Conference on Aerospace Sciences \& Aviation Technology, Paper: ASAT-13-PP-22, Military Technical College, Cairo, Egypt, May 2009.

[17] R. B. Bid, E. W. Stewart, and E. N. Lightfoot, Transport Phenomena. Revised, John Wiley \& Sons, 2nd edition, 2007.

[18] M. J. Sidi, Spacecraft Dynamics and Control, Cambridge University Press, 1997.

[19] T. M. Chiasson, Modeling the characteristics of propulsion systems providing less than $10 \mathrm{~N}$ thrust [M.S. thesis], Department of Aeronautics and Astronautics, Massachusetts Institute of Technology, 2012. 

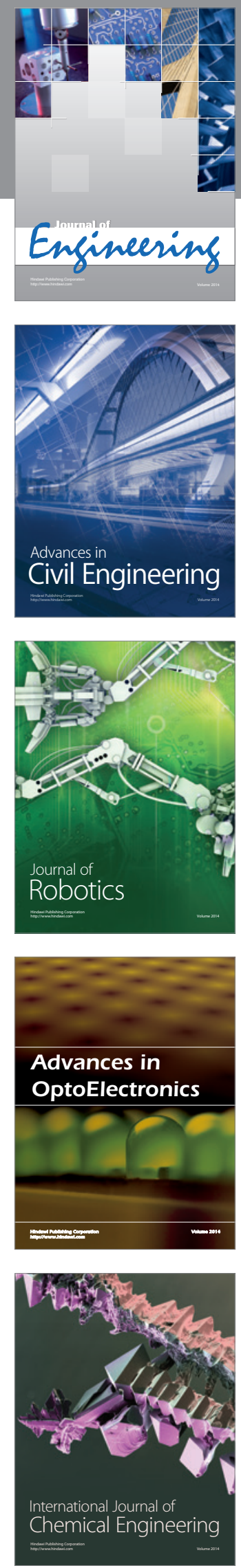

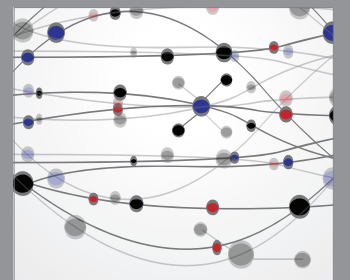

The Scientific World Journal
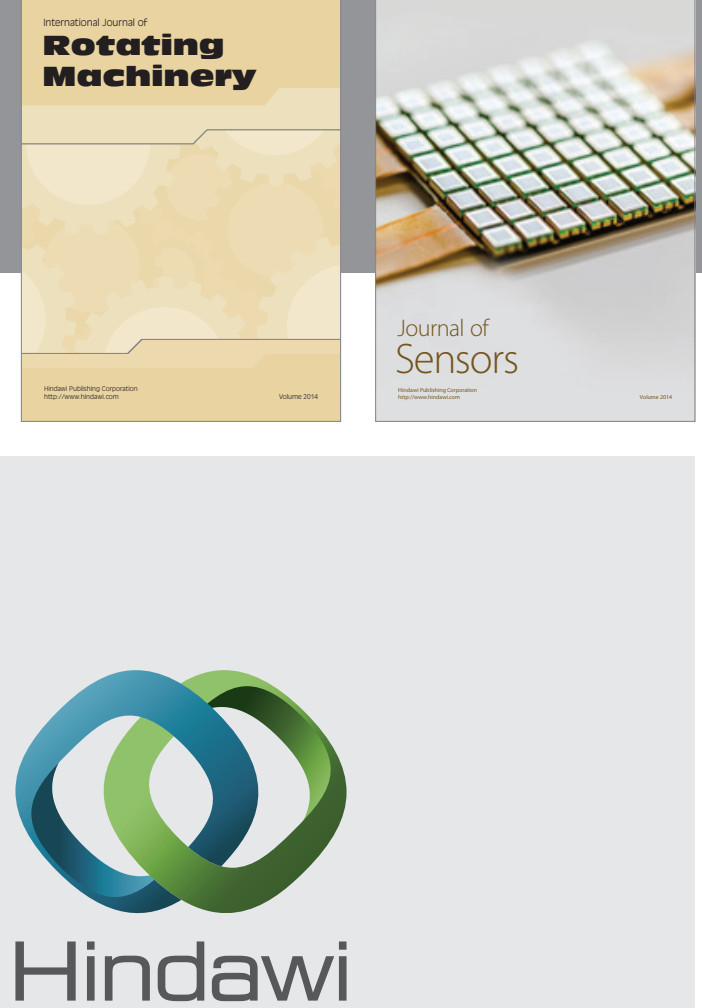

Submit your manuscripts at http://www.hindawi.com
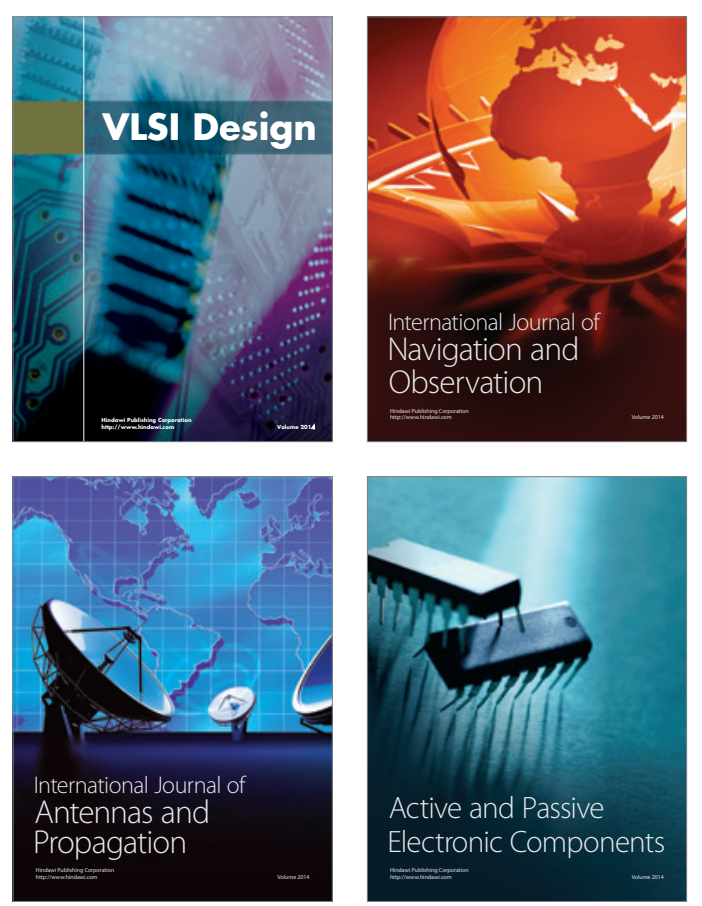
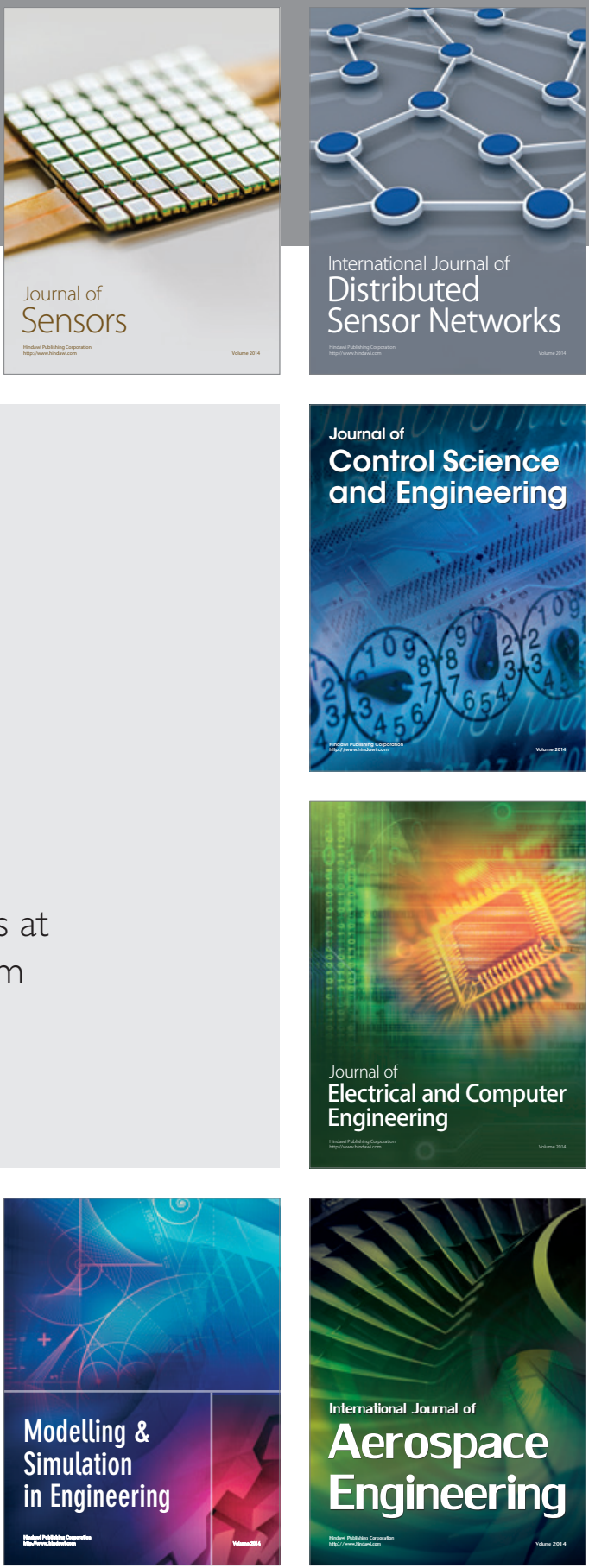

Journal of

Control Science

and Engineering
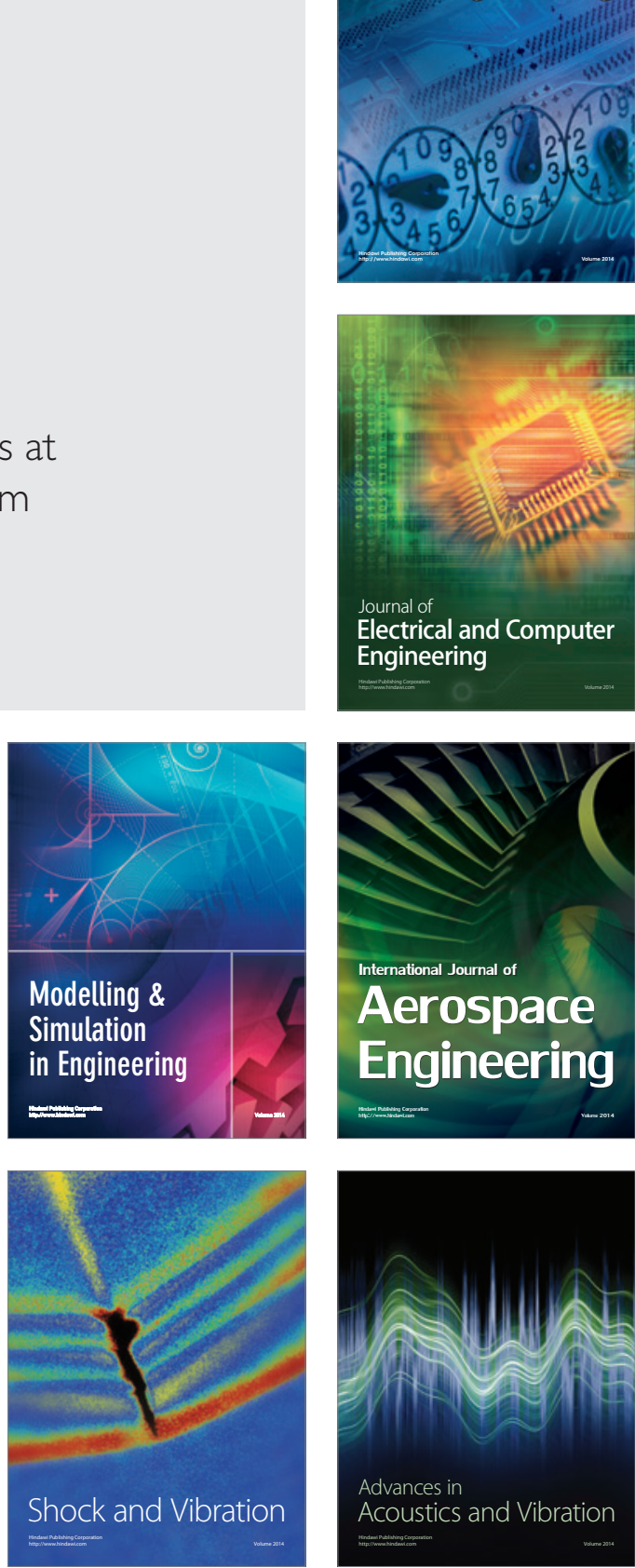